to be tested? Did hunter-gathers maximize their foraging? What effects might the packing of several social groups into a landscape have on the feasibility of seasonal movements? These are questions of interest and importance in archaeological modelling of prehistoric ecology, but in very few cases has it been possible to obtain evidence to test intuitive answers.

Fortunately, archaeologists are optimists who continue to pursue their enquiries Micawber-like, and in the last few years they have been rewarded. It has emerged that to some extent humans are what they eat. Diet affects the composition of bone in various ways and subtle signals, indicative of various aspects of the subsistence regime, may be preserved in prehistoric skeletons. For instance, in any given region the calcium to strontium ratio at the time of death can be used to separate pure herbivores from pure carnivores and to establish a scale of mixed diets ${ }^{2,4}$. In addition, the carbon- 13 composition of bones can serve as a measure of the relative dietary contribution of $\mathrm{C}_{3}$ and $\mathrm{C}_{4}$ plants; for example, the spread of maize into the woodlands of North America has been monitored in that way ${ }^{5,6}$. Nitrogen isotopes, along with carbon isotopes, are providing measures of the relative importance of seafoods and legumes in some ancient diets ${ }^{7-9}$.

Thus, in recent years, aspects of stable isotope chemistry and human bone biology have become important in studies of prehistoric subsistence systems, such as that reported by Sealy and van der Merwe in this issue ${ }^{1}$. Their investigation took as its starting point what must surely rank as one of the most sustained and informative archaeological studies of regional huntergatherer subsistence and land-use patterns, carried out over some fifteen years by a group at Cape Town University led by John Parkington ${ }^{10}$. It has monitored responses that span a sequence of environmental change starting 20,000 years ago. Amongst other things, Parkington suggests that there existed at some stage a strong pattern of seasonal migration of human groups between the coast and an inland range of mountains. A series of sites with evidence of complementary seasons of occupation make the model plausible and attractive. But is it correct?

Sealy and van der Merwe report an ingenious and painstaking investigation of bone composition, which they use to explore the question of seasonal movement. Extensive measurements of a full range of coastal foods show that they have markedly different carbon-13 abundances from a full range of mountain foods (be they plant or animal). From this, it is possible to predict the isotope content of bones from people on a coastal diet, a mountain diet or the mixed diet that would indicate seasonal migration between the coast and inland mountains. Tested against the predictions, the compositions of bones do not sustain the hypothesis of extensive seasonal migra- tion of the same people between the two habitats.

Although the results hold out promise that bone-composition studies will sometimes provide otherwise unavailable information about prehistoric ranging patterns and the use of food from different ecozones, the findings in this particular case must be seen as provisional. The samples of skeletons from each time period and each zone are small and need enlarging. Careful alternative modelling of various mixed diets will also need to be considered. Nevertheless, the patterns seem consistent enough to be highly suggestive that, attractive though it may have seemed even then, spending summer in the Alps and winter on the Riviera was not always feasible in prehistoric times.

1. Sealy, J. \& van der Merwe, N.J. Nature 315, 138 (1985).

2. Schoeninger, M.J. Museum of Anthropology, Univ. Michigan Tech. Rep. 9 (1979).

3. Schoeninger, M.J. Paleorientology 7, 73 (1981).

4. Sillen, A. \& Kavanagh, M. Ybk phys. Anthr. 25, 67.

5. van der Merwe, N.J. \& Vogel, J.C. Nalure 276, 815 (1978).

6. van der Merwe, N.J. Am. Sci. 70, 596 (1982).

7. De Niro, M.J. \& Epstein, S. Geochem cosmochim Acta 45, 341 (1981).

8. Schoeninger, M., De Niro, M.J. \& Tauber, H. Science 220 , 1381 (1983).

9. Farnsworth, P., Brady, J.E., De Niro, M. \& MacNeish, R.S. Am. Antiq. 50, 102 (1985).

0. Parkington, J.E. in Advances in World Archaeology (ed. Wendorf, F. \& Close, A.) 89 (Academic, London, 1984).

Glynn Ll. Isaac is in the Department of Anthropology, Peabody Museum, Harvard University, Cambridge, Massachusetts 02138, USA.

\title{
Meterology
}

\section{What limits front formation?}

\section{from K.A. Emanuel}

FOR many years, meteorologists and oceanographers were perplexed by the tendency of fluid flows to form 'fronts', or near discontinuities, in such properties as temperature, salinity gradients and velocity. These fronts, which occur in both the atmosphere and oceans, seem to defy the general tendency of turbulent flows to smooth out strong gradients of fluid properties. Then, in 1972, B.J. Hoskins and F.P. Bretherton (J. atmos. Sci. 29, 11; 1972) developed an attractive theory which clearly explained the dynamics of front formation and which predicted the formation of real discontinuities in density gradients and velocity. This presented meteorologists with a new problem: why do actual fronts consist of zones of strong gradients, spread out over horizontal distances on the order of several tens of kilometres, rather than of real discontinuities?

It is natural to suppose that turbulent mixing limits the gradients found in real fronts and, until recently, it was assumed that the mature frontal zone represents a balance between the dynamics of front formation and their dissipation by turbulence. Recently, however, I. Orlanski and B.B. Ross (J. atmos. Sci. 41, 1669; 1984) have suggested that frontal collapse may be at least partially limited by processes that do not involve turbulent mixing. Their conclusions stem from the results of numerical simulations of atmospheric fronts, making use of the full equations that describe the conservation of momentum, heat and mass, rather than the approximate forms used in the Hoskins-Bretherton model.

These approximate equations, which can sometimes be solved analytically and which have proved extremely useful in advancing the conceptual picture of front formation, are based on an assumption of cross-front geostrophic balance - that is, forces arising from pressure gradients across the front are assumed to be balanced by Coriolis accelerations acting on the component of wind parallel to the front. This approximation can be shown to be valid during most of the time it takes for density gradients to collapse but it eventually breaks down near the time of formation of discontinuities. When this happens, the cross-front pressure gradient force may be balanced by actual particle accelerations across the front as well as by Coriolis accelerations. The numerical simulations carried out by Orlanski and Ross seem to show that these effects tend to limit rate of front formation, at least, and perhaps also the ultimate amplitude of the cross-front gradient of front-parallel velocity.

As Orlanski and Ross point out, an exact interpretation of the numerical simulations is problematical. It is generally necessary to represent some turbulent mixing to keep the time integration stable, and it is not clear what role this diffusion plays in limiting the numerically simulated fronts. Detailed evaluation of the dynamics of the simulated fronts is also hampered by the finite horizontal resolution of numerical models. (In this case, the horizontal distance between grid points is $61.5 \mathrm{~km}$.)

Finally, it is well known that near discontinuities can form in non-rotating fluids in which the balance in the frontal zone involves no Coriolis accelerations; taken together with present results this implies that, while both purely inertial and purely geostrophic fronts are limited by turbulent mixing, fronts involving both inertial and Coriolis accelerations may be limited by a non-diffusive mechanism.

This non-intuitive idea, if true, presents a startingly different view of the dynamics of mature fronts in the atmosphere and oceans. More work with numerical models and better observations of frontal zones should help assess its validity.

K.A. Emanuel is at the Center for Meterology and Physical Oceanography, Cambridge, Massachussetts 02139, USA. 